\title{
Past, Present \& Future: Rangelands in China
}

\section{Here we examine rangelands and changes in pastoral use in an ethnic-minority region, Gansu, China.}

\author{
By Donald J. Bedunah and Richard B. Harris
}

$\mathrm{R}$ angelands of western China have historically supported a pastoral economy and large wildlife populations, but recent social, political, and economic changes are affecting pastoralists and wildlife. We examined rangeland issues and concerns in Jianshe Township of Aksai Kazak Autonomous County, in western Gansu Province, People's Republic of China (Jianshe, hereafter) during 1997-2000 as part of a larger study examining argali and domestic sheep interactions.

Our rangeland study included a rapid rangeland reconnaissance and interviews with pastoralists and local government officials on their perspectives on changes and issues. Livestock production from extensive rangelands is the primary economic activity within Jianshe, but these same rangelands are also habitat to a number of important wild species including argali, wild yak, and snow leopard. Balancing domestic livestock production, while maintaining healthy wild populations of large mammals, is a concern of local government officials.

Here, we provide an overview of Jianshe, describe its rangelands, current and historical practices of Kazak pastoralists, and discuss issues and concerns related to the conservation of this area.

\section{Overview Of Jianshe}

Jianshe is one of four townships in the Aksai Kazak Autonomous County in Gansu Province. The county was created from portions of Gansu, Qinghai, and Xinjiang Provinces in 1953 to provide grazing and administrative services for Kazak pastoralists who fled Xinjiang during the 1930 's to avoid persecution (Yang 1993) $)^{1}$. Jianshe has an area of 3.3 million acres, but a population of only about 600 . The Jianshe area is administered by Gansu, but Chinese maps show this area as being in Qinghai (Fig.1).

The landscapes of Jianshe vary from magnificent mountain glaciers towering above narrow and wide mountain valleys of grass and shrub vegetation, sand

\footnotetext{
Most of the roughly 1.1 million Kazaks in Chinta today still live in Xinjiang (Benson and Svanberg 1998).
}

dunes as high as 300 feet near the Kharteng River, and shrub deserts and desert devoid of vegetation occur at lower elevations. Elevations vary from about 10,000 feet on the Kharteng River to 18,420 feet on the highest peak. No weather stations exist in Jianshe, but at the 6 closest weather stations annual precipitation varies from 0.6 inches to 11.2 inches with about $80 \%$ of the precipitation received between May and September.

In addition to argali and wild yak, wild ungulates present include Tibetan wild ass, blue sheep, and Tibetan and goitered gazelle. Predators include wolves, Eurasian lynx, dholes, brown bears, snow leopards and eagles.

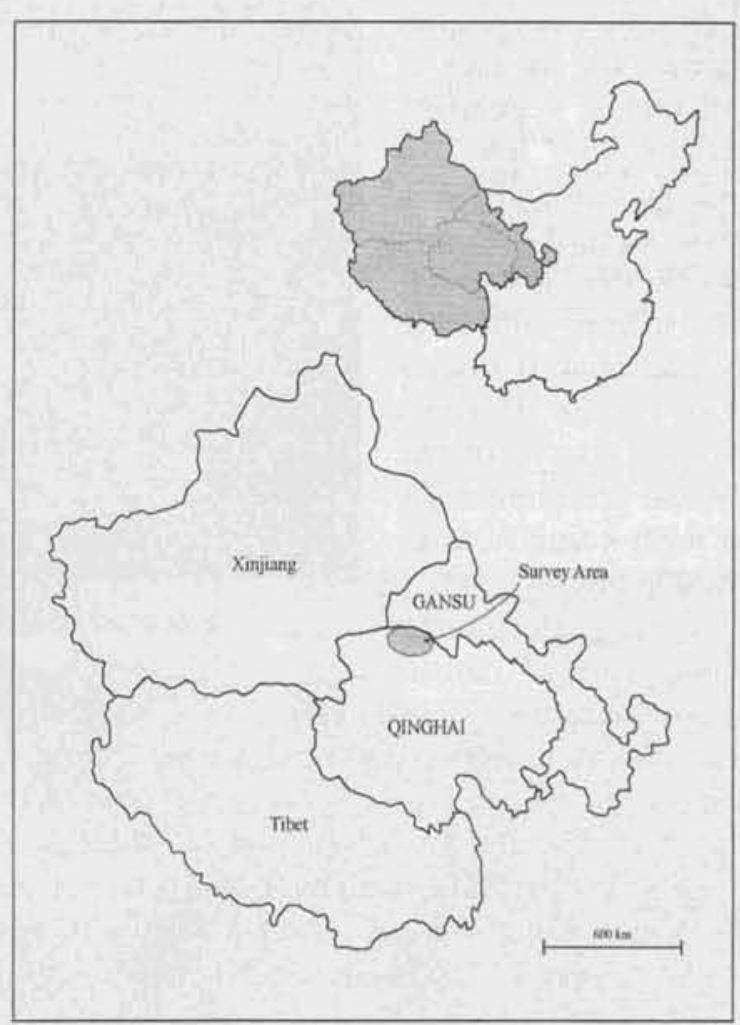

Figure 1. Location of Jianshe Township, Aksai County, Gansu Province, China. Note that although administered by Gansu, Jianshe is located within Qinghai Province as displayed on most national maps. Inset: Location of Gansu and Qinghai Provinces, as well as Xinjiang and Tibetan Autonomous Regions within China. 
Common and scientific names of some of the wildlife of Jianshe Township

\begin{tabular}{|l|l|}
\hline Argali & Ovis ammon \\
\hline Blue sheep & Pseudois nayaur \\
\hline Tibetan gazelle & Procapra picticaudata \\
\hline Goitered gazelle & Gazella subgutturosa \\
\hline Wild yak & Bos grumiens \\
\hline Wild ass or Kiang & Equus kiang \\
\hline White-lipped deer & Cervus elaphus \\
\hline Snow leopard & Panthera uncia \\
\hline Wolf & Canis lupus \\
\hline Eagles & Aquila chrysaetos and A. rapax \\
\hline Dholes & Cuon alpinus \\
\hline Lynx & Felis lynx \\
\hline Brown Bear & Ursus arctos \\
\hline
\end{tabular}

Many of these species may affect or be affected by herders using these rangelands.

\section{Rangeland Types}

The elevations of most livestock ranges are between 10,400 and 13,650 feet. At higher elevations there are no frost-free days. At the lower elevation rangelands are warmer, but the lack of rainfall makes vegetation production very low. No trees are present and rarely do shrubs exceed 2 feet in height. Herders and wildlife have to cope with large yearly and spatial differences in forage. Herders today, and likely in the past, raise predominately sheep with some horses, camels, and goats.

We have grouped the rangeland types of Jianshe into 4 broad groups based on elevation, climate or with special moisture conditions: (1) a semi-desert type, (2) a dry, alpine grassland type (3) an alpine dwarf-shrub type, and (4) a wetland type. In Jianshe, these 4 types comprise about 1.2 million acres. Large areas of desert and steep mountainous areas of rock and ice-fields comprise approximately 1.2 million acres and 0.9 million acres, respectively.

Semi-Desert Rangeland. The semi-desert type is located at relatively low elevations ( 10,000 to 11,500 feet), between desert and the cold, high grassland type, and is used predominately as winter range. Vegetation is domi- nated by low shrubs such as Sympegma regelii and Reaumaria soogorica. Grasses such as Stipa gobica, $S$. glareosa, Leymus paboanus and Achnatherum splendens are of low coverage, but can be important on some areas in forming a semi-desert grassland.

Dry, Alpine Grassland. The dry, alpine grassland is a bunchgrass type that occurs along many of the larger river valleys and into mountain valleys and alpine belts in the adjacent mountains. This type is similar to the alpine steppe described by Miller and Schaller (1996). The dry, alpine grasslands are found between 11,500 to 13,000 feet, but at higher elevations the type forms discontinuous belts where it connects with small, localized areas of alpine cushion plant communities and large areas of alpine dwarf-shrub communities.

Alpine Dwarf-Shrub. The alpine dwarf-shrub type is a dry, high elevation low shrub type dominated by Krascheninnikovia latens. Stipa glareosa, a shortstatured needlegrass, is the dominant herbaceous species, but it is generally of very low coverage. Vegetation communities are simple with mainly alpine species, but Stipa purpurea, a valuable forage can be common in transitional areas. The elevation varies from about 12,000 to 14,300 feet and these areas are used

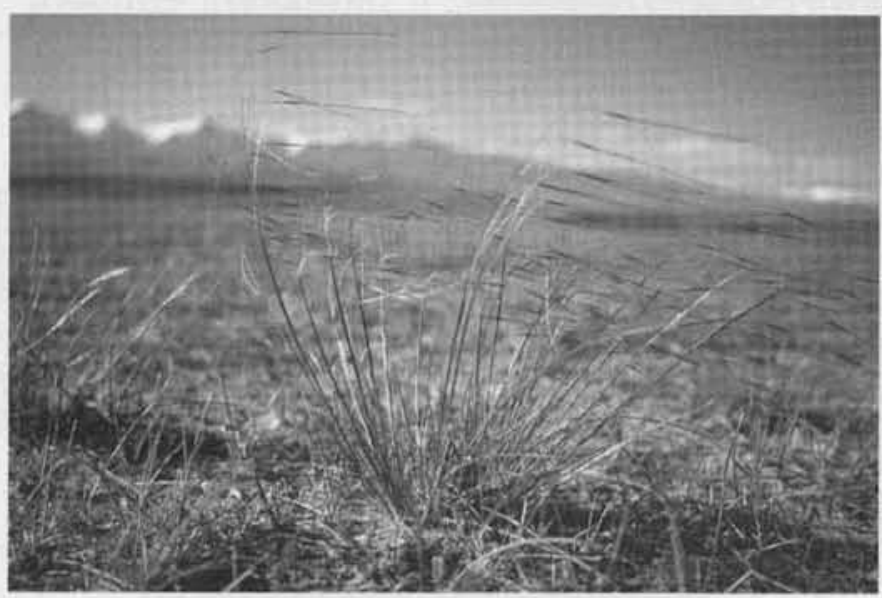

Purple needlegrass (stipa purpurea) in flower. mostly as summer and autumn ranges by pastoralists.

On many sites Krascheninnikovia latens makes up $90 \%$ of the plant cover and is by far the most important forage species in the alpine dwarf-shrub type. Walter and Box (1983) report that this species flowers only after 25 years, lives for 100 to 300 years, and the root system has a mass 10 to 12 times that of the shoot system. In Jianshe, herders also use this shrub as a fuel source because little other wood is available, burning the crowns and upper roots. We found these alpine low-shrub types often damaged by human activities such as fuel collections and heavy grazing, especially near camps. Recovery from this damage is a very long process in the high elevation and low productivity conditions of these sites.

Wetland Types. Wetlands vary from desert oases, to riparian sites along rivers and streams, to wet meadow along alpine streams. These sites are extremely important because of their productivity and diversity, but the amount of total area occupied by wetland types in Jianshe is small, comprising about $1 \%$ of the total area. In general, 


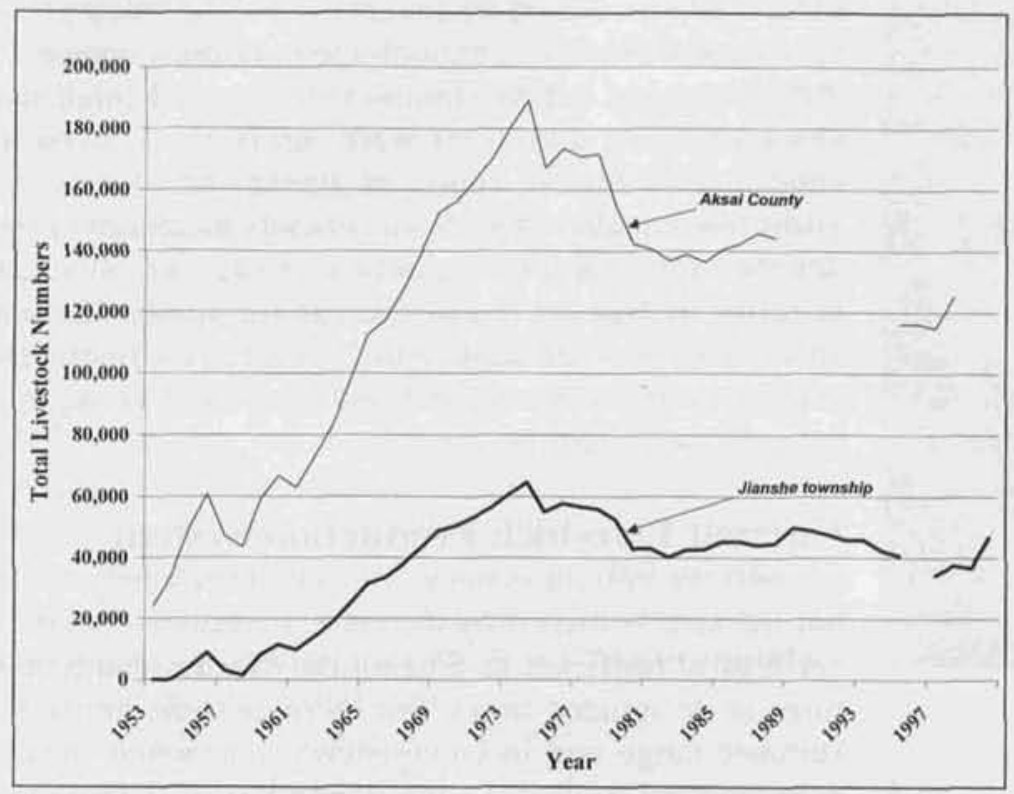

Figure 2. Trend of total livestock numbers in Aksai County and Jianshe Township, 1953-1999. Source: Aksai County Economic Statistics Handbook.

these wetland types are dominated by sedges and are much more productive than the surrounding vegetation.

\section{History Of Pastoralism In Jianshe}

The pastoralists historically using the Jianshe area were Mongols. Ancient pictographs in the area are of Mongolian origin, as are remnant wolf-traps made of rock. According to our interviews, the number of Mongols and their livestock that historically lived in this area were very low.

Kazaks began moving into the area in the early 1930's from Xinjiang, and their gradual migration continued through the 1940's (Aksai County 1985, Yang 1993). Due in part to their long travel over inhospitable desert terrain, livestock numbers were initially very low. At this time, Kazak pastoralists managed livestock in their traditional system where family groups lived in yurts and raised livestock mostly for household use (Bessac 1990, Benson and Svanberg 1998). Kazak settlers also supplemented their diet liberally with wild game during their early years in the Kharteng valley (Aksai County 1985, Yang 1993).

During the 1960 's, a large number of

"Han" Chinese people moved to Jianshe. Most immigrants were farmers and workers from Wuwei in central Gansu who fled unemployment and starvation during the Great Leap Forward and Cultural Revolution. These migrations were evidently voluntary, and not part of a speseen today. cific government program, although outmigration from poverty stricken areas in eastern Gansu has been government policy at times (World Bank 1988). Since the 1960 's, occasional undocumented migration (i.e., movements without changing household registration) by Han agriculturalists from the Wuwei area into Jianshe has continued. We know of no other high elevation pastoral area in western China where herding has been taken up by so many Han Chinese.

During China's communal period (roughly 1960-1983 in this region) all pastoralists of Jianshe were organized into the Jianshe People's Commune. Livestock numbers dramatically increased (Fig. 2). As in most Chinese communes during this time, no livestock were privately owned, and compensation to pastoralists was in "work points" rather than cash. The Commune attempted to develop irrigation for growing hay and cultivate introduced grasses to improve productivity. An administrative center was built near summer pastures (but far from the nearest paved road), houses and corrals for livestock operations were built, and wells were dug. Growing hay and irrigating Jianshe's high elevation rangelands failed because of saline soils and difficult climate. Ultimately, the commune system was abandoned and considered a failure, but there is little doubt that the land use changes during this period resulted in large areas of rangeland degradation that can still be

When the Jianshe People's Commune was disbanded and the "household responsibility system" established in 1983 , livestock were distributed to the membership, and

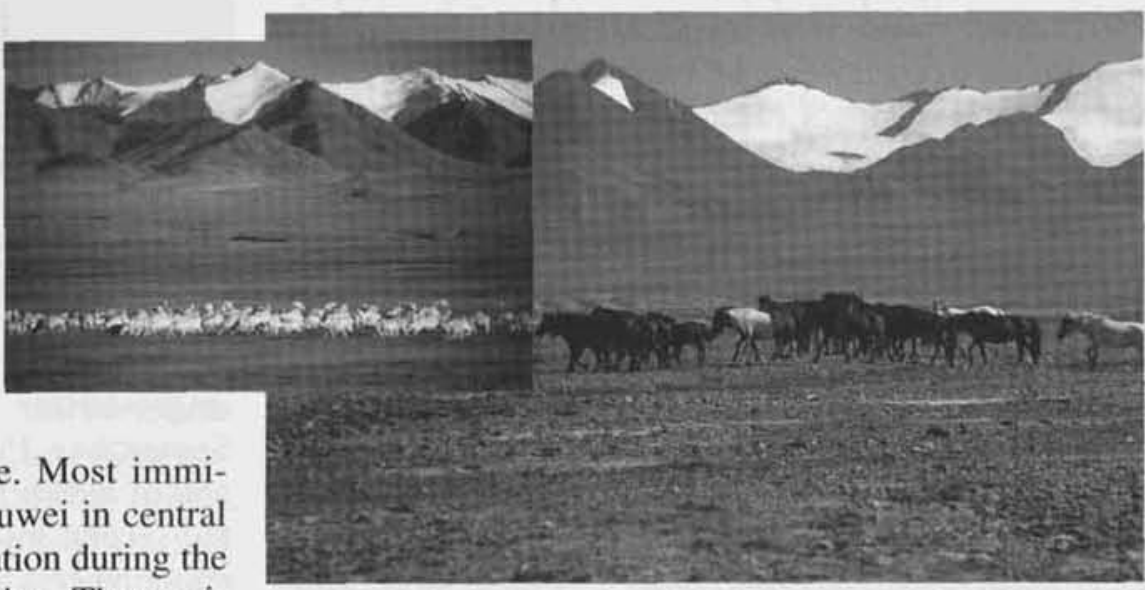

Horses /sheep grazing in sparsely vegetated alpine rangeland. 


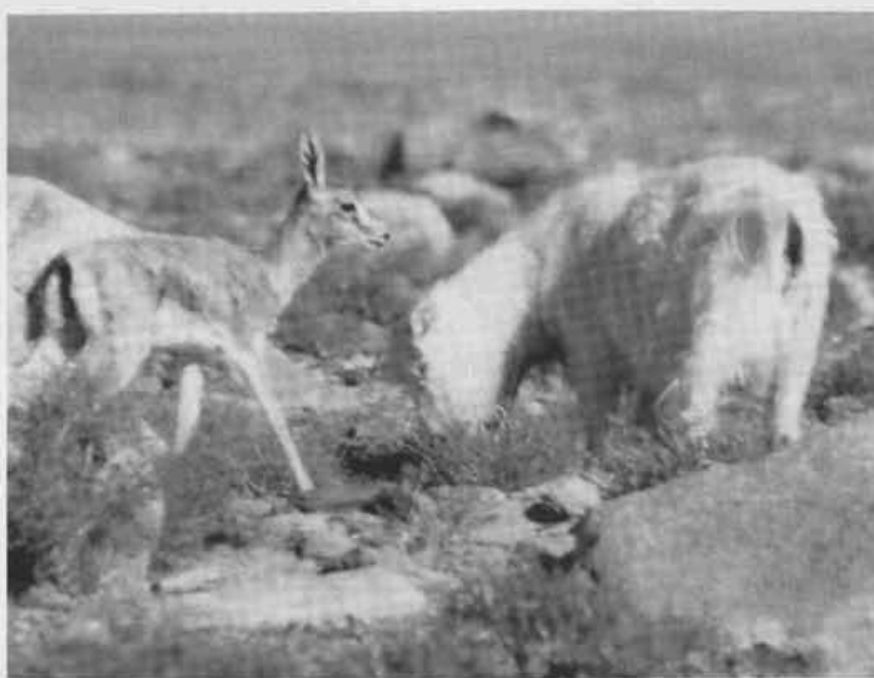

Gazelle fawn grazing with domestic goats.

seasonal pastures were allocated to all households. Seasonal ranges were allocated based partly on history in the region; Kazaks generally received spring ranges in the lowest elevation areas. Han immigrants arriving in the 1960 's received preferential areas for spring in slightly higher elevation areas. Later immigrants were allocated the least preferred spring areas. At distribution each family was provided herds in the amount of 70 head per family member. Early on, rules required that herd size remain at that size, but these rules were later abandoned.

Kazak pastoralists continued to be the majority of users of Jianshe rangelands until the 1990's. Following the establishment of independent Kazakhstan in 1991, Chinese Kazaks who met specified criteria were allowed by the Chinese government to immigrate to the newly independent state. A number of Kazak families in Jianshe took advantage of this opportunity in the early 1990 's and there was a subsequent decrease in livestock numbers. As of 1999 , only 16 of about 100 livestock operations in Jianshe were owned by Kazak families, the remainder being owned by Han. Most owners (about $90 \%$ ) contracted out the herding work and lived in Aksai's county seat. Even among the 16 remaining Kazak family-owned herds, 7 used contracted labor. This pattern contrasts sharply with the practice among Kazaks of the Altay region in Xinjiang (Banks, 2000), where $80 \%$ did their own herding even during winter.

Thus, by the time of our study in the late 1990's, the largely Kazak-owned herds had given way to a Han majority, and traditional pastoral practices had been largely replaced by inexperienced contract herders who originated from other regions of western China. These contract herders considered herding a short-term position until they could find more pleasant work. Jianshe's pop- ulation had decreased by roughly $40 \%$, the small primary school was closed, school-aged children boarded at the county seat school, families no longer herded livestock together, and yurts were rarely seen. Even the small administrative center of Jianshe had taken on a ghost-town quality, with town officials maintaining residences in the far-away county seat, staying only temporarily in Jianshe itself. Except for spring lambing sheds, pastoral "encampments" generally consisted of small patchwork tents inhabited by 1 or 2 young men entrusted with herding duties.

\section{Current Livestock Production System}

Under the current system, livestock is privately owned but the land is owned by the state. Livestock operations are legally restricted to grazing only in designated pastures at designated times, but there is some latitude in summer range and in emergencies (e.g. when snow is excessive the county grazing bureau can allow livestock to use other areas). Seasonal ranges are not fenced; instead, most are based on recognizable geographic features.

Spring ranges are grazed from late February to midJuly. All spring pastures are centered on lambing structures made of adobe and mud. Summer pastures are grazed from mid-July to late September and herders find summer grazing areas the least limiting. We interviewed two older Kazak herders that had recently started shar-

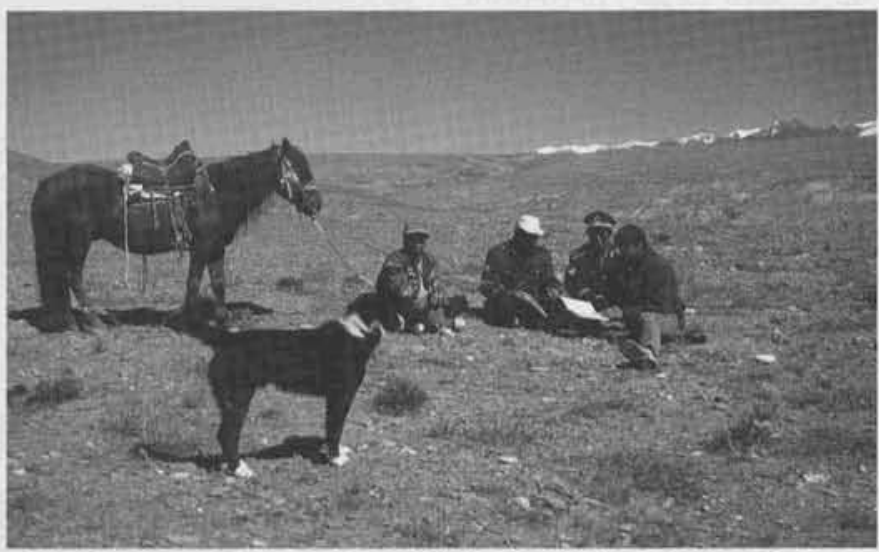

Author (Don Bedunah) with Forestry Bureau staff interviewing young Han herder.

ing summer pastures and herding responsibilities, but in general, herders do not share labor. Autumn pasture is intermediate in elevation and is grazed from late September 25 to mid-November. Winter pasture is grazed between mid-November to late-February, and is the second most rigidly defined and defended. Winter encampments are generally stationary through the entire winter season. 
Pastoralists have been free to ply the open market since the disbanding of communes and initiation of the household responsibility system in 1983 . According to county officials, there has never been a mandated quota that must be provided to the state, or sold to the state at lower-than-market prices, unlike reports from elsewhere in pastoral China (Cincotta et al. 1992, Thwaites et al.1998). However, there have always been a series of taxes and fees on livestock and land use.

In 1999 there were officially about 37,000 sheep and goats in autumn (after yearly herd reductions through sales) and approximately 1,000 each horses and camels. During our interviews we learned that all official statistics on animal numbers are under-estimated by approximately $20 \%$. Apparently, this underestimation has been done for some time and serves as a de-facto insurance policy for herders that can suffer significant livestock losses at times. Livestock numbers decreased through the 1990's and were about $17 \%$ lower in 1999 than 1990 , although, livestock numbers have increased again in the last few years (Fig. 2).

Historically, goats have accounted for about $5 \%$ of total livestock numbers, but in recent years have risen to about $20 \%$ because of high value of cashmere in comparison with other livestock products. Camels have also increased but horses have decreased, due in part to governmentsponsored encouragement to reduce horse numbers.

Wolves, eagles, and dholes are the major predators on sheep and goats and there are occasional losses from bears. However, predation was not viewed as a major concern by herders we interviewed.

\section{Issues And Threats To Pastoralism}

Maintaining and improving rangeland productivity for livestock and wildlife is a primary concern for the Aksai government. Although no long-term monitoring has been done, county officials and herders with a long-history in the area stated that rangeland conditions have deteriorated. They informed us of a general loss of vegetative cover and productivity of many areas, and were specific in mentioning reductions of a few plant species, e.g., willows and a low growing juniper used for fuel. Both of these species are almost gone now. Older herders stated that in many areas it is now more difficult to find vegetation to use as fuel than in the past.

As is common on many rangelands, overgrazing was apparent near camps, especially spring camps. However degradation was evident in almost all spring pastures, and herders and local officials also remarked about their decreasing quality. Longworth and Williamson (1993) reported that in 1990 one-third of rangeland in Gansu Province was considered as degraded, with about one-half of the degraded area considered "severely degraded".

The household responsibility system for pastoralists has been criticized as exacerbating, rather than alleviating, problems of overgrazing in Inner Mongolia (Thwaites et al. 1998, Williams 1996) and Ningxia (Ho 2000). Miller (2002) also stresses the concern that current livestock production systems in many of the pastoral areas of China are not sustainable and that large tracts of China's rangelands are now degraded. We are concerned that current grazing policy does not allow for adequate rangeland recovery or provide enough flexibility for the herders to move livestock. Allowing herders flexibility and mobility is a very useful tool for management of livestock in these highly non-equilibrium environments.

Government programs have attempted to provide pastoralists with seasonal grazing pastures, but have also required herders to use specific pastures at specific times with limited opportunities to vary grazing patterns. Rangelands of Jianshe were likely stocked near capacity during the last 30 to 40 years resulting in few areas that could function as reserve pastures during drought conditions. A grazing system that allowed for more rested pastures or reserve pastures would benefit wildlife and pastoralists. Seasonal pastures are grazed at the same time each year in the same manner (same livestock and movement patterns).

Certainly many of the past grazing problems have been associated with changes in the pastoral system and increased numbers of herders and livestock using these rangelands. However, because of the current situation, (relatively large numbers of livestock for the available management, absentee owners, many inexperienced herders, and no apparent land ethic of either contract herders or herd owners), we believe rangeland sustainability of Jianshe is threatened by current livestock management. 


\section{Management \& Monitoring Needed}

The socio-economic changes in China during the $20^{\text {th }}$ Century have resulted in increased numbers of people and livestock using the rangelands of Jianshe and have altered traditional pastoral systems. The consequence of the high number of contract herders, reduction in the proportion of Kazaks, and the fact that even Kazaks lacked a long history in this area, is evidence that there is little "traditional ecological knowledge" in herding practices and that "ties to the land" have been severed. Herding has become a job (and apparently not an attractive job) instead of a lifestyle, and many of the new contract herders had no previous experience.

These rangelands continue to support significant wildlife and an important livestock production system for the county. However, we believe the present pastoral system consisting of large numbers of inexperienced herders will require a more active management and monitoring program by land managers to ensure sustainable use of these rangelands for both pastoralists and the wildlife that utilize these areas.

Authors are professor, School of Forestry and Research Associate, Wildlife Biology, University of Montana.

\section{References}

Aksai County. 1985. A brief of Aksai Kazak Autonomous County. Gansu Ethnic Publishing House. 155 pp. (in Chinese).

Banks, T. J. 2000. Economic reform and the Chinese commons: A tale of three villages. Paper presented at $8^{\text {th }}$ Biennial Conference of the International Assoc. for the Study of Common Property, Bloomington, IN. Web address: www.indiana.edu/ iascp/iascp2000.htm.
Benson, L. and I. Svanberg. 1998. China's last nomads: The history and culture of China's Kazaks. M.E. Sharpe, Armonk, N.Y,

Bessac, F. 1990. Winter at Timurlik, 1949-1950. Presentation at the workshop "The Kazakhs on the Sino-Soviet Frontier: National Identities and the Transformation of Tradition", University of Southern California, Los Angeles, California, December 14-15, 1990.

Cincotta, R. P., Y. Q. Zhang, and X. M. Zhou. 1992. Transhumant alpine pastoralism in northeastern Qinghai Province: An evaluation of livestock population response during China's agrarian economic reform. Nomadic Peoples 30:3-25.

Ho, P. 2000. China's rangelands under stress: A comparative study of pasture commons in the Ningxia Hui Autonomous Region. Development and Change 31:385-412.

Longworth, J. W. and G.J. Williamson. 1993. China's Pastoral Region. CAB International, Oxford, UK.

Miller, D. J. 2002. The importance of China's nomads. Rangelands 24: 22-24.

Miller, D. J. and G. W. Schaller. 1996. Rangelands of the Chang Tang Wildlife Reserve in Tibet. Rangelands 18:91-96.

Thwaites, R., T. de Lacy, Y. H. Li, and X. H. Liu. 1998. Property rights, social change, and grassland degradation in Xilingol Biosphere Reserve, Inner Mongolia, China. Society and Natural Resources 11:319-338.

Walter, H. and E.O. Box. 1983. The Pamir-An ecologically well-studied high-mountain desert biome, p. 237-269. In: West, N.E. (ed), Ecosystems of the World 5. Temperate Deserts and semi-deserts. Elsevier Scientific Publishing Co., New York.

Williams, D. M. 1996. Grassland enclosures: Catalyst of land degradation in Inner Mongolia. Human Organization 55:307-313.

World Bank. 1988. China: Growth and Development in Gansu Province, A World Bank Country Study. The World Bank, Washington, D.C. 454 pp.

Yang Y. Z. 1993. Minority Areas in Gansu Province. Gansu Nationalities Press. Lanzhou, Gansu, P.R.C. 644 pp. (in Chinese). 